\title{
Analysis and Supplement with the Mechanism of Electrosynthesizing Benzofurnan Derivatives
}

\author{
Yunhui Li, Jie Zhou, Xiuxia Gao, Feifei Wang \& Yupeng Wang \\ School of Chemistry and Environmental Engineering \\ Changchun University of Science and Technology \\ Changchun 130022, China \\ E-mail: liyh@cust.edu.cn
}

\begin{abstract}
Davood Nematollahi et al. have successfully electrosynthesised a series of benzofuran derivatives in the presence of nucleophile agents. Base on their experimental result, we analyzed the electron density of the intermediate during benzofuran derivatives synthesis and reached the same conclusions as that of Davood Nematollahi et al..Therefore, the method of electron density analysis is proven to be correct and expected to have a wide applications. But after we analyzed the electron density of 2-aldehyde-p-quinone(1a) and 3-carboxyl-o-quinone(7a), we have different opinions with theirs. The electron density of C-6 position of the 2-aldehyde-p-quinone lower than the that of C-5 position leads to the final product 6 when electrochemical oxidation of the 2,5-dihydroxybenzaldehyde. For 2,3-dihydroxybenzoic acid case, since the competition between the carboxyl of the $\mathrm{C}-2$ position and the carboxyl of the C-1' position in the 3-carboxyl-o-quinone and the hydrogen transferred to the carboxyl of the C-1' position, there will be a rearrangement before the next electrochemical oxidation and the final product 21 will be formed.
\end{abstract}

Keywords: Eletroorganic, Rearrangement, Electron density

\section{Introduction}

Benzofuran derivatives constitute a major group of the nature's collection of biologically active heterocycles. (Nematollahi, D., 2007, p.3646-3651). They are usually important constituents of plant extracts used in traditional medicine (Csekei, M., 2004, p.285-291). and effective as antitumor agents( Hayakawa, I., 2004, p.3411), antidepressants (Gaszner, P., 2006, p.14), antihypertensives and cytotoxic(Banskota, A. H., 2000, p.1277-1279.).

A series of benzofuran derivatives have been electrosynthesised in the presence of nucleophile agents using cyclic voltammetry and controlled-potential coulometry methods by Davood Nematollahi et al. (Nematollahi, D., 2000, p.208-214. Afkhami, A., 2005, p.5633-5640. Fakhari, A. R., 2007, p.3894-3898. Fakhari, A. R., 2005, p.205-210.Nematollahi, D., 2004, p.591-595).To synthesize new benzofuran derivatives Davood Nematollahi et al. studied the electrochemical oxidation of benzenediols in aqueous solutions and in the presence of a variety of nucleophiles derived from CH acids.((a)Nematollahi, D., 2003, p.1639-1644 (b)Nematollahi, D., 2004, p.2637-2640 (c)Nematollahi, D., 2004, p.31-37).

In this direction, they investigated the electrochemical oxidation of catechols in the presence of â-diketone such as acetylacetone(Nematollahi, D., 2005, p.638-644) and dimedone. (Nematollahi, D., 2007, p.3646-3651. Nematollahi, D., 2003, p.1639-1644). As a lot of works and studies have been done, they concluded the similar mechanisms of electrochemical oxidization followed with the Michael addition reactions in the electrosynthesis of the parent-starting molecule showed as Scheme 1.

After we studied the mechanics and data of experiments by Davood Nematollahi et al. in details, we are mysterious about some questions:1) would do the nucleophile agents attack the same position of the carbon of the intermediates while the $\mathrm{R}^{2}$ is different, such as methoxy and carboxyl, and $\mathrm{R}^{1}$ is same:2) if is there an effect of $\mathrm{R}^{2}$ on the position where the nucleophile agents attack and how about the effect. Based on these questions, we analyze the electron density of the intermediates and proved our ideas with the aid of the calculation and the data reported.

\section{The analysis of the electron density}

Davood Nematollahi et al. reported that 3-methoxy-o-quinone is attacked in C-5 position by 2-mercaptobenzoxazole leading to the formation of 5-(Benzo[d]oxazol-2-ylthio) -3-methoxybenzene-1,2-diol (Nematollahi, D., 2005, 
p.7769-7772).They successfully illustrated that the process as Scheme 2 is disadvantage for the reaction.

We studied the process by the analysis of the electron density of the 3-methoxy-o-quinone. Initailly, the electron cloud of carbon of benzene is set as the standard and signed as $\delta$. Then the carbon of 3- methoxy -o-quinone (2d) is assigned with a number which is shown as Figure 1(A).

Since connecting the oxygen directly, the electron cloud of C-1, C-2, C-3 position is lower than $\delta$ and signed as $\delta^{+}$. There is a conjugated structure among the C-1, C-6, C-5 as Figure 1(B) shown which leads the higher electron cloud of C-6 position than $\delta$ (signed as $\delta^{-}$). While the electron cloud of C-5 should be $\delta^{+}$. Since the connection of C-3, C-4, C-5 and C-6 is similar to the butadiene, the electron cloud of C-4 should be $\delta$. As a result, an graphics of electron cloud of 3- methoxy -o-quinone is shown as Figure $1(\mathrm{C})$. Then it would be found that the electron density of C-5 position is lower than that of the C-4 position according to Figure 1(C). The nucleophile agent attacks the carbon of lower electron density firstly, and the C-4 position is forbidden to be attacked, Scheme 2 would not happen during the process. Our conclusion is consistent with the result of Davood Nematollahi et al. which means that the method in the analysis of electron density is reasonable.

The electrochemical oxidation of 2,5-dihydroxybenzaldehyde(1) in the presence of 3-hydroxy-1H-phenalen-1-one has also been reported1. But there is no reasonable explanation why the 2-aldehyde-p-quinone is attacked in the C-5 position, not the C-6 position in the reference. Therefore, we analyze the electron density of carbons in benzene rings of 2-aldehyde-p-quinone.

Every carbon of the intermediate 2-aldehyde-p-quinone is assigned with a number and shown as Figure 2(A). Assuming that the electron density of the C-5 and the C- 6 would be equal at first, then their electron density would be affected by the neighbor carbons which are in the three conjugated structures shown as Figure 2(B), Figure 2(C), Figure 2(D) respectively.

In Figure 2(B), the $\mathrm{C}-2$ position shows $\delta^{-}$and the $\mathrm{C}-3$ position shows $\delta^{+}$. Because of the effect of the steric hindrance of the carboxyl of the C-1', the C-3 position is difficult to be attacked by the nucleophile agent. The C-5 position and C-6 position should be affected by the electron density of the C-1 and the C-4 shown as Figure 2(C), Figure 2(D) respectively.

In Figure 2(C), there would be two reasonable situations: a) the C-6 showing $\delta^{+}$and the C-5 showing $\delta^{-}$; b) the C-6 showing $\delta^{-}$and the C-5 showing $\delta^{+}$. In Figure 2(D), the case a should be the only reasonable situation. If the C-5 showing $\delta^{+}$, then the $\mathrm{C}-3, \mathrm{C}-4, \mathrm{C}-5$ all showing $\delta^{+}$result in the unstable structure. So the C-6 shows $\delta^{+}$and the C-5 shows $\delta$ as Figure 2(E) and the electron density of C-6 position is lower than that of the C-5 position. Then the nucleophile agent intends to attack the C-6 position first conduce the final product 6 shown as Figure 3(B).

For further proving our conclusion, the $\sigma$ value of $1 \mathrm{H} \mathrm{NMR}$ in the $\mathrm{C}-\mathrm{a}$ position and $\mathrm{C}-\mathrm{b}$ position shown as Figure 3(A), Figure 3(B) respectively are calculated by the following experiential formula(1):

$$
\sigma=7.26+\sum S
$$

Where $\mathrm{S}$ is the sum of the chemical shifts for the substituents.

And the $\sigma$ value of $13 \mathrm{C}$ NMR of the hydrogen in the $\mathrm{C}$-a position and C-b position is also calculated as the sum of a series of constants by the following equation(2):

$$
\sigma=128.5+\sum A
$$

Where $\mathrm{A}$ is the sum of the chemical shifts for the substituents.

The calculated and experimental results are shown in Table 1:

Comparing the calculation value with the experimental data, it will be found that the $\delta$ value of $1 \mathrm{H}$ NMR and $13 \mathrm{C}$ NMR of C-b is much closer to the experimental data, so the structure of Figure 3(B) is more reasonable. Therefore, it is logical to propose the process shown as Scheme 3. Since we consider the ring of furan equal to the combination of a methoxy and an ethyl when we calculate, there is a small difference between the calculated value and the experimental data.

\section{Mechanism Analysis -Intramolecular Rearrangement}

The electrochemical oxidation of 2,3-dihydroxybenzoic acid in the present of 3-hydroxy-1H-phenalen-1-one has been reported by Davood Nematollahi et al. (Nematollahi, D., 2007, p.3646-3651). After we studying the data of characterization of the products in the reference, we find that there is much similarity between the product 13 (the structure is shown as Figure 5(A)) and the product 20d(the structure is shown as Figure 6(A)). Their experimental data shows as Table 2 and Table 3(In order to forbid confusion, we use the 13 and 20d signed by Davood Nematollahi et al. here). 
Compare with the $\sigma$ value of $1 \mathrm{H}$ NMR of the product 13 and the product $20 \mathrm{~d}$ according to Table 2 , we find that the $\sigma$ value are same at 7.25, 9.07, 10.39 and uniform at 7.81 8.60(where there are six apex in the 13 and at the homologous position there is a broad apex in the 20d). The difference of the aldehyde of the 13 and the carboxyl of the $20 \mathrm{~d}$ reflects at 13 and 12.92. It is reasonable to conclude that the position of the hydrogen on the 13 and $20 \mathrm{~d}$ is uniform. According to Table 3 .

The comparison of the $\sigma$ value of 13C NMR of the product 13 and the product $20 \mathrm{~d}$ is shown as Table 3 . The $\sigma$ value are same at 99.1,111.9,116.7,120.3,125.2,125.3,127.5,127.8,129.6,130.6,132.5,132.6,135.8,141.8,146.5,149.1,159.8,168.2. The experimental data between 13 and $20 \mathrm{~d}$ reflect that the position of carbon on them are uniform. Combining with the conclusion of Table 2, we draw the conclusion that 13 and $20 \mathrm{~d}$ have the same structure. So it is reasonable to present the structure as Figure 4(B) shows.

For further proving our conclusion, the $\sigma$ value of 1H NMR and 13C NMR in the C-c and C-d position is calculated with the equation (1) and equation (2). The calculated and experimental results are shown in Table 1. According to the calculation value and the experimental data, it will be found that the $\delta$ value of $1 \mathrm{H}$ NMR and $13 \mathrm{C}$ NMR of C-d is much closer to the experimental data, so the structure of Figure 4(B) is more reasonable.

The carbon of 3-carboxyl-o-quinone is assigned with a number which is shown in Figure 5(A) and the structures that main effect the electron density of the C-4 position and the C-5 position are shown as Figure 4(B) and Figure 4(C) respectively.

Similar analysis of the electron density is taken and we find that the electron density of the C-4 and the C-5 position are all showing as $\delta^{+}$. But because of the effect of the steri hindrance of the carboxyl of the C-1', the C-4 position is difficult to be attacked by the nucleophile agent. So there is an advantage that the nucleophile agent attacks the C-5 position.

Since there is a di-carboxyl conjugated with the $\mathrm{C}=\mathrm{C}$ of $\mathrm{C}-3$ and $\mathrm{C}-4$ position shows as Figure $5(\mathrm{C})$, the following hydrogen transfer has two reasonable ways shows as Figure 6(A), Figure 6(B) respectively. When the hydrogen transfers to the $\mathrm{C}-3$ position, it should move to the carboxyl of C-1' position because the carboxyl and the hydroxyl in the $\mathrm{C}-1$ ' position are conjugated. It is advantaged to form $9 \mathrm{~b}$. So the process shows as Figure 6(B) is dominant.

It is unstable that there is two hydroxyl at the same carbon of $9 \mathrm{~b}$ and one hydroxyl will leave making the transfer of hydrogen between the C-4 position and the C-1' position. Then the hydroxyl on the C-1' position attacks the C-4 position and the two atoms became close with each other and the $\mathrm{C}-\mathrm{O}$ bond formation. As the hydroxyl is connected to the $\mathrm{C}-4$ position, there is a 1,6- $\sigma$ transfer between the $\mathrm{C}-1$ position and the $\mathrm{C}-1$ ' position because there is a resuming aromaticity tendency. After a molecule of water attacks the $\mathrm{C}^{+}$and leaves a proton, the intermediate 16a is formed. The final product 21 is formed after the electrochemical oxidation of the 16a and an subsequent intramolecular cyclization. The details are shown as Scheme 4.

Compared with 6(the structure shows as Figure 3(B)) and 21(the structure shows as Figure 4(B)), we find that the two construction are consistent. With the consideration of discussion above, the process of Scheme 3 and Scheme 4 agreed with the experimental data.

\section{Conclusion}

Base on the experimental data of Davood Nematollahi et al., we draw the same conclusion by analyzing the electron density of the 3-methoxy-o-quinone and prove that the analysis method is correct. The electron density of C-6 position of the 2-aldehyde-p-quinone is lower than the C-5 position bringing the final product 6 when electrochemical oxidation of 2,5-dihydroxybenzaldehyde. For 2,3-dihydroxybenzoic acid case, there is a intramolecular rearrangement before the subsequent electrochemical oxidation reaction because of the nuclephic agents attacks the C-5position and the final product(21) get.

\section{Acknowledgment}

The analysis is on the boot of the Mechanisms and the data of the electrosynthesis of the benzofurnan dericatives that the papers Davood Nematollahi reported. Thanks for their factuality and the experimental data.

\section{References}

Afkhami, A., Nematollahi, D., Madrakian, T. \& Khalafi, L. (2005). Investigation of the electrochemical behavior of some catecholamines in the presence of 4-aminobenzoic acid. Electrochimica Acta., 50(28), 5633-5640.

Banskota, A. H., Tezuka, Y., Midorikawa, K., Matsushige, K. \& Kadota, S. (2000). Two Novel Cytotoxic Benzofuran Derivatives from Brazilian Propolis. J. Nat. Prod., 63, 1277-1279.

Csékei, M., Novák, Z., Timári, G. \& Kotschy, A. (2004). The 'one-pot' preparation of substituted benzofurans. Arkivoc, 285-291.

Fakhari, A. R., Nematollahi, D. \& Moghaddam, A. B. (2005). Electrochemical study of catechols in the presence of 
4,6-dihydroxy-2-methylpyrimidine . J. Electroanal. Chem., 577(2), 205-210.

Fakhari, A. R., Nematollahi, D., Shamsipur, M. \& Makarem, S. et al. (2007). Electrochemical synthesis of 5,6-dihydroxy-2-methyl-1-benzofuran-3-carboxylate derivatives. Tetrahedron Letters., 63, 3894-3898.

Gaszner, P., Miklya, I. (2006). Major depression and the synthetic enhancer substances, (-)-deprenyl and R-(-)-1-(benzofuran-2-yl)-2-propylaminopentane. Prog. Neuro-Psychopharmacol. Biol. Psychiatry, $30,14$.

Hayakawa, I., Shioya, R., Agastuma, T., Furokawa, H. \& Sugano, Y. (2004). Thienopyridine and benzofuran derivatives as potent anti-tumor agents possessing different structure-activity relationships. Bioorg. Med. Chem. Lett., 14 , 3411 .

Nematollahi, D., Amani, A. \& Tammari, E. (2007). Electrosynthesis of Symmetric and Highly Conjugated Benzofuran via a Unique ECECCC Electrochemical Mechanism: Evidence for Predominance of Electrochemical Oxidation versus Intramolecular Cyclization. J. Org. Chem., 72 (10), 3646-3651.

Nematollahi, D., Tammari, E. (2005). Electroorganic Synthesis of Catecholthioethers. J. Org. Chem., 70 (19), 7769-7772.

Nematollahi, D., Forooghi, Z. (2003). ECEC and ECE-Type Mechanisms in Electrochemical Oxidation of 4-Substituted Catechols in the Presence of 4-Hydroxy-6-methyl-2-pyrone. Electroanalysis, 15(20), 1639-1644.

Nematollahi, D., Habibi, D., Rahmati, M. \& Rafiee, M. (2004). A Facile Electrochemical Method for Synthesis of New Benzofuran Derivatives. J. Org. Chem., 69(7), 2637-2640.

Nematollahi, D., Rafiee, M. (2004). Electrochemical oxidation of catechols in the presence of acetylacetone. J. Electroanal. Chem., 566(1), 31-37.

Nematollahi, D., Rafiee, M. (2005). Diversity in electrochemical oxidation of dihydroxybenzoic acids in the presence of acetylacetone. A green method for synthesis of new benzofuran derivatives. Green Chem., 7, 638-644.

Nematollahi, D., Golabi, S.M. (2000). Investigation of the electro-methoxylation reaction: Part 1. Electrochemical study of 4-tert-butylcatechol and 3,4-dihydroxybenzaldehyde in methanol. J. Electroanal. Chem. 481(2), $208-214$.

Nematollahi, D., Tammari, E., Sharifi, S. \& Kazemib, M. (2004). Mechanistic study of the oxidation of catechol in the presence of secondary amines by digital simulation of cyclic voltammograms. Electrochimica Acta., 49(4), 591-595.

Table 1. Comparison of the $\sigma$ value of $1 \mathrm{H}$ NMR and the 13C NMR by calculation and experiments

\begin{tabular}{|c|c|c|c|}
\hline \multirow{3}{*}{${ }^{1}$ H NMR } & \multicolumn{2}{|c|}{ the result of calculation } & experimental data \\
\hline \multirow{3}{*}{} & C-a & 6.67 & 7.25 \\
\cline { 2 - 4 } & C-b & 6.95 & 7.25 \\
\cline { 2 - 4 } & C-c & 6.32 & 7.25 \\
\cline { 2 - 4 } & C-d & 7.24 & 7.25 \\
\hline \multirow{3}{*}{${ }^{13}$ C NMR } & C-a & 109 & 116.7 \\
\cline { 2 - 4 } & C-b & 116 & 116.7 \\
\cline { 2 - 4 } & C-c & 103.8 & 116.6 \\
\cline { 2 - 4 } & C-d & 116.2 & 116.6 \\
\hline
\end{tabular}


Table 2. Comparison of $1 \mathrm{H}$ NMR of the product 13 and the product $20 \mathrm{~d}$

\begin{tabular}{|c|c|c|c|}
\hline \multicolumn{3}{|c|}{$\begin{array}{l}\text { The sign of the formula of the product the } \\
\text { molecular }\end{array}$} & the experimental data of ${ }^{1} \mathrm{H}$ NMR \\
\hline 13 & $\mathrm{C}_{20} \mathrm{H}_{10} \mathrm{O}_{5}$ & \multicolumn{2}{|c|}{$\begin{array}{c}7.25(\mathrm{~s}, 1 \mathrm{H}, \text { aromatic }), 7.81(\mathrm{t}, J=7.4 \mathrm{~Hz}, 1 \mathrm{H} \text {,aromatic), } \\
7.91(\mathrm{t}, J=7.3 \mathrm{~Hz}, 1 \mathrm{H} \text {, aromatic }), 8.28,8.35(\mathrm{dd}, J=8.2 \\
\mathrm{Hz}, J=6.4 \mathrm{~Hz}, 2 \mathrm{H}, \text { aromatic }), 8.44(\mathrm{~d}, J=7.6 \mathrm{~Hz}, 1 \mathrm{H}, \\
\text { aromatic), } 8.57(\mathrm{~d}, J=7.1 \mathrm{~Hz}, 1 \mathrm{H} \text {,aromatic),9.07(s,1H, } \\
\mathrm{OH}), 10.40(\mathrm{~s}, 1 \mathrm{H}, \mathrm{OH}), 13 \text { (broad, } 1 \mathrm{H}, \text { aldehyde) }\end{array}$} \\
\hline $20 d$ & $\mathrm{C}_{20} \mathrm{H}_{10} \mathrm{O}_{6}$ & $\begin{array}{r}7.25(\mathrm{~s}, 1 \\
9.07(\mathrm{~b}\end{array}$ & $\begin{array}{l}\text { matic),7.88-8.60 (broad, 6H, aromatic), } \\
\text { H, OH),10.39 (broad, 1H, OH), } 12.92 \\
\quad \text { (broad, } 1 \mathrm{H}, \text { acid) }\end{array}$ \\
\hline
\end{tabular}

Table 3. Comparison of 13C NMR of the product 13 and the product 20d

\begin{tabular}{|c|c|c|c|}
\hline \multicolumn{3}{|c|}{$\begin{array}{l}\text { The sign of the formula of the product } \\
\text { the molecular }\end{array}$} & the experimental data of $13 \mathrm{C} \mathrm{NMR}$ \\
\hline 13 & $\mathrm{C}_{20} \mathrm{H}_{10} \mathrm{O}_{5}$ & \multicolumn{2}{|c|}{$\begin{array}{l}99.1,111.9,116.7,120.3,125.2,125.3,127.5,127.8,129.6, \\
130.6,132.5,132.6,135.8,141.8,146.5,149.1,159.8,168.2\end{array}$} \\
\hline $20 \mathrm{~d}$ & $\mathrm{C}_{20} \mathrm{H}_{10} \mathrm{O}_{6}$ & \multicolumn{2}{|c|}{$\begin{array}{c}99.1,111.9,116.6,116.8,120.3,125.1,125.4,127.5,127.8 \\
129.6,130.6,132.5,132.6,135.8,141.8,146.5,149.1,159.9 \\
168.2,179.1\end{array}$} \\
\hline
\end{tabular}

SCHEME 1<smiles>[R]c1c(O)ccc(O)c1[R]</smiles><smiles>[R]c1c(O)ccc(O)c1[R]</smiles>

\section{SCHEME 2}<smiles>O=CC1=CC=CC(=O)C1=Cc1cc2c(cc1C=O)oc1nc(Sc3ccc(O)c(O)c3C=O)ccc12</smiles> 


\section{SCHEME 3}
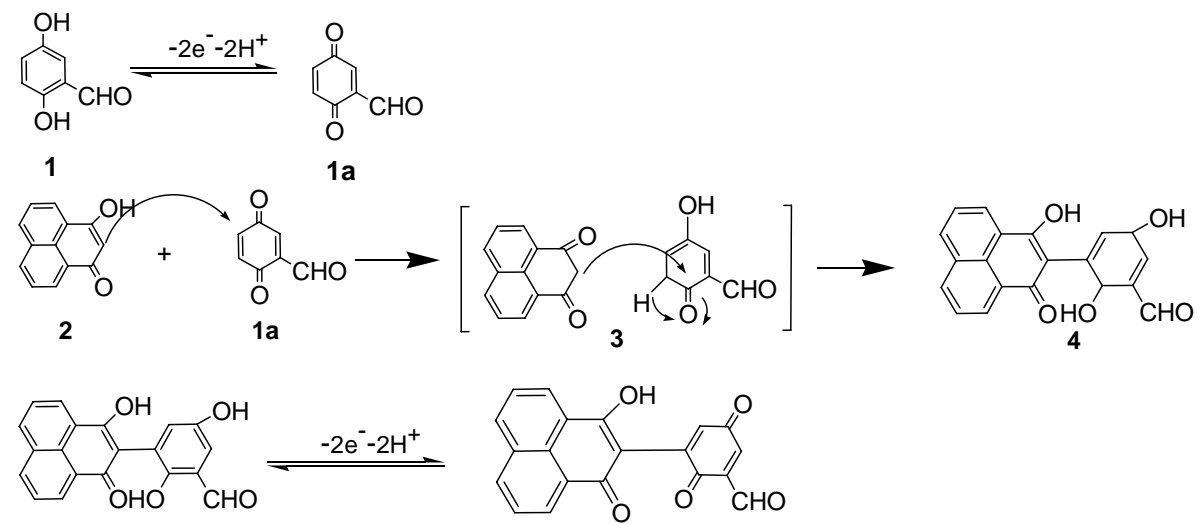

4

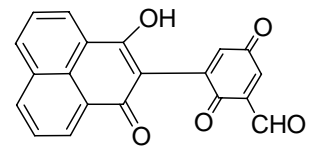

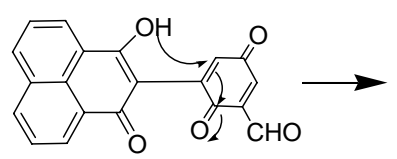

$4 a$

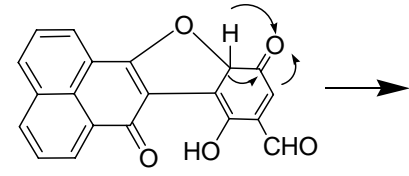

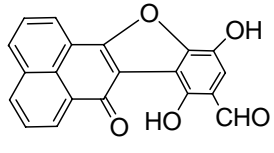

6

Scheme 4

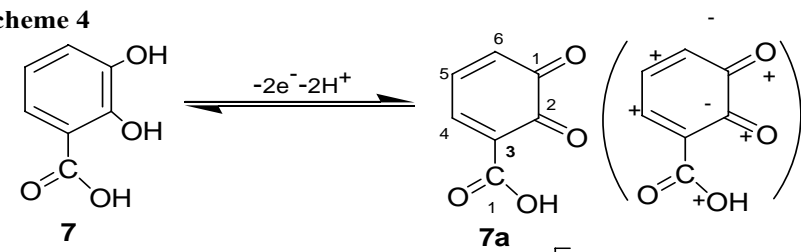

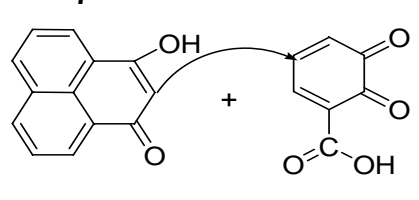

2

$7 a$
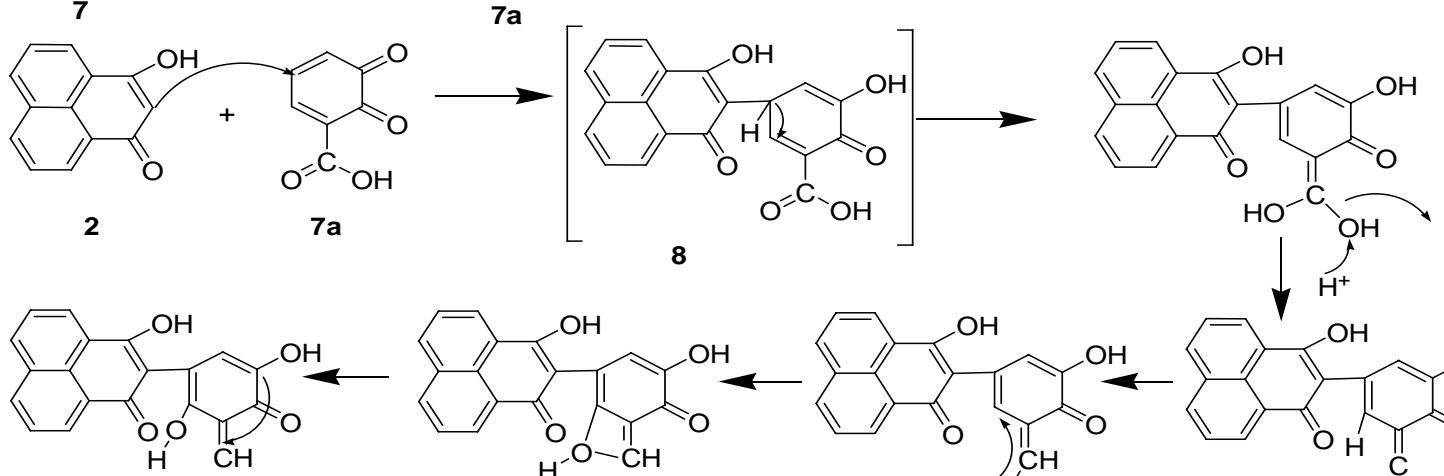

13

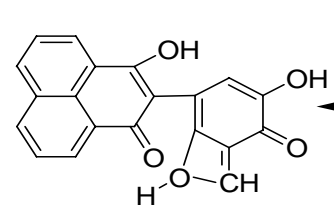

12
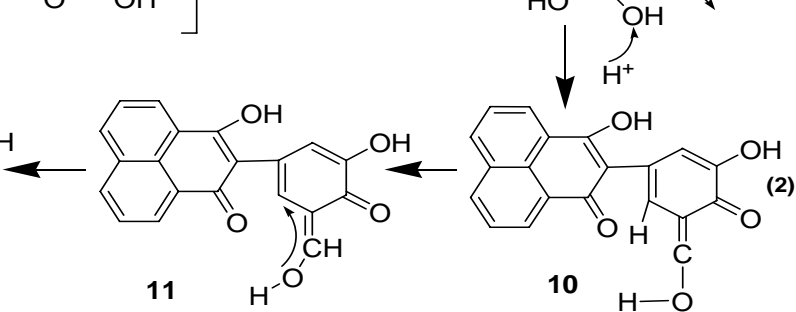

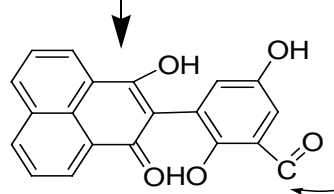

14

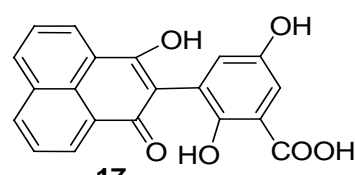

17

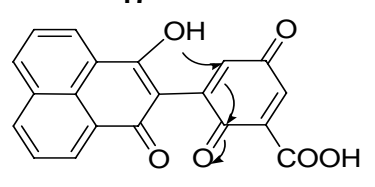

19

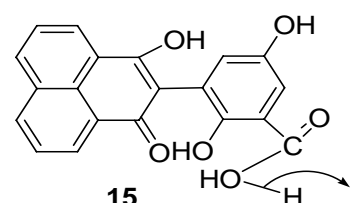

15

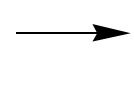

$(+) \mathrm{H}^{-}$

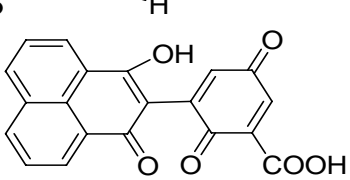

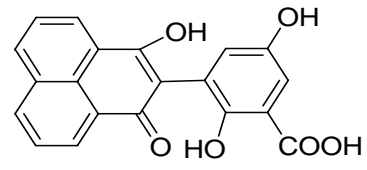

16

(3)

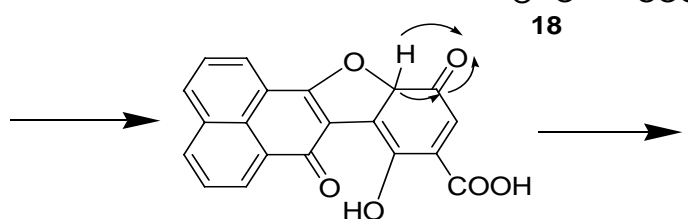

20

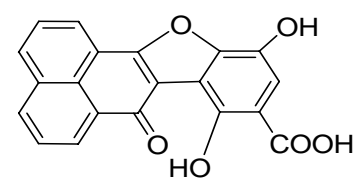

21 
<smiles>COC1=CC=CC(=O)C1=O</smiles>

A<smiles>C=CC=O</smiles>

B

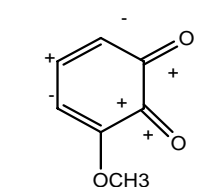

C

Figure 1. The number assigned and the electron density of the carbon of 3-methoxy-o-quinone<smiles>O=CC1=CC(=O)C=CC1=O</smiles>

A<smiles>O=CC=[O+]</smiles><smiles>C=CC(=O)[O-]</smiles>

C<smiles>C=CC(=O)[OH+]</smiles>

D<smiles>O=CC1=[O+]C(=O)C(=O)C=[O+]C1=O</smiles>

E

Figure 2. The number assignment and the electron density of the 2-aldehyde-p-quinone

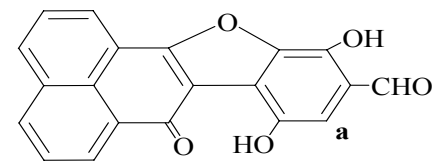

A

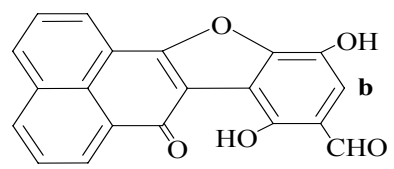

B

Figure 3. The finally product of electrosynthesis 2,5-dihydroxy-benzo aldehyde (A) Davood Nematollahi reported (B) our result

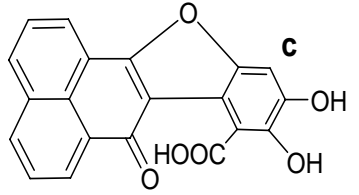

A

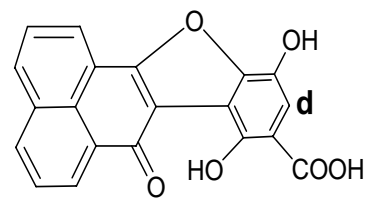

B

Figure 4. The finally product of electrosynthesis 2,3-dihydroxybenzoic acid (A) Davood Nematollahi reported (B) our result<smiles>O=C(O)C1=CC=CC(=O)C1=O</smiles>

A<smiles>O=C[C-]=[O+]</smiles>

B<smiles>O=C([O-])C(=[OH+])[Se-]</smiles>

C

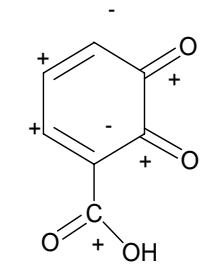

D

Figure 5. The number assignment and the electron density of 3-carboxyl-o-quinone 
A:
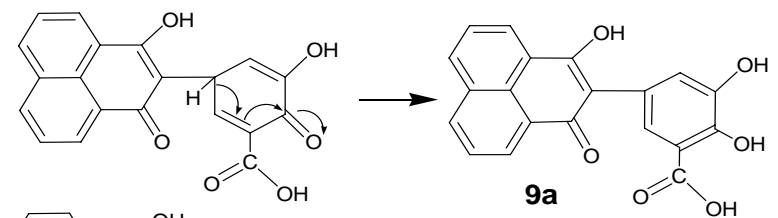

B:
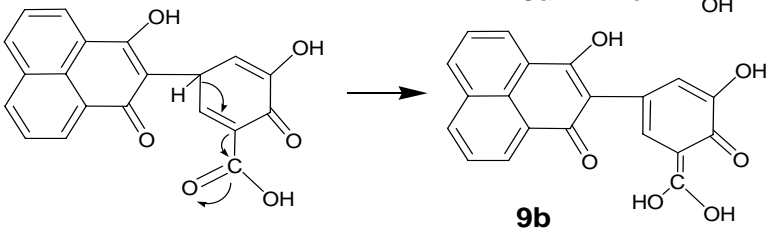

Figure 6. The two ways of the hydrogen transfer between the caboxyls of the $\mathrm{C}-2$ position(A) and the $\mathrm{C}-1$ ' position(B) 